\title{
Algorithm optimization for PWM signal generation with selective harmonic elimination using the Walsh transform
}

\author{
Jesús Vicente-Rodrigo $^{1}$, Rafael Pindado-Rico ${ }^{2}$, Inmaculada Martínez-Teixidor ${ }^{3}$ \\ Department of Electronic Engineering \\ Campus Terrassa-Manresa, Universitat Politècnica de Catalunya \\ Av. Bases de Manresa, 61-73, 08240 Manresa (Spain) \\ ${ }^{1}$ Tel: (+34) 9387772 55, Fax: (+34) 9387772 02, jesusv@eel.upc.es \\ 2 Tel: (+34) 9373982 19, Fax: (+34) 9373980 16, pindado@eel.upc.es \\ 3 Tel: (+34) 9387772 54, Fax: (+34) 9387772 02, imma@eel.upc.es \\ URL: http://www.upc.es
}

\begin{abstract}
The use of the Walsh transform in DC-AC PWM waveform generation allows the calculation of the switching angles by means of linear equations dependent on the fundamental amplitude.

After the description of the mathematical method used to find the solutions, it is presented a method to reduce the computation time needed to find all the switching intervals that give a useful range variation of the fundamental amplitude.
\end{abstract}

\section{Key words}

Algorithm optimisation, PWM inverters, Selective harmonic elimination, DC-AC conversion, Walsh transform.

\section{Introduction}

It is well known that programmed harmonic reduction in DC-AC PWM waveforms needs for the solving of non linear equations that made its application difficult in real time control of the fundamental amplitude. In these cases, a common choice is the off-line calculation of the switching angles, which establishes a dilemma between the desired precision and the memory capacity needed.

The use of the Walsh functions [1] is a mean for the linearization of the equation set that lead to the harmonic cancellation that permits the on-line calculation of the switching angles as a linear function of the fundamental amplitude [2] [3]. With this technique the use of $\mathrm{M}$ angles per quarter of period permits the cancellation of M-1 harmonics and the regulation of the fundamental amplitude.

Harmonic reduction in PWM DC-AC converters using the Walsh transform has been studied by the authors, in previous published works, in different aspects: method description [4], non idealities of the switching pulses [5], computation of the harmonic distortion [6] and evaluation of active and reactive power [7]. In those works, it has been developed a method that allows the calculation of the switching angles as linear equations dependent on the fundamental amplitude.

However, this technique has the drawback of obtaining a great number of solutions that difficult the selection process of the better cases and also increments the computation time, especially when a big number of switching intervals is used.

Figure 1 shows the harmonic amplitudes of the PWM waveforms for all the intervals with solution for 4 switching angles for a quarter period, with a fundamental amplitude regulation above $20 \%$. It is considered the medium value of the fundamental amplitude $\left(\mathrm{A}_{1}\right)$ range available for each interval vector.

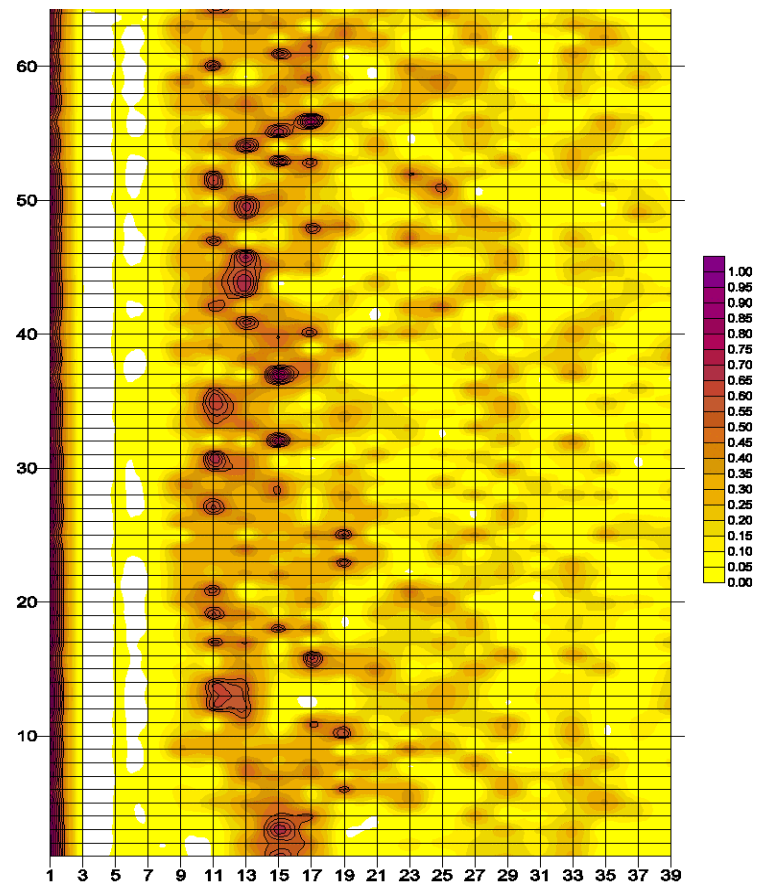

Fig. 1. Harmonic distribution for intervals with A1 range above $20 \%$. X axis: Order of harmonic, Y axis: Interval vector 
This representation helps in the analysis of the obtained results, since easily allows the determination of those interval vectors with a better harmonic reduction. The chosen order is the increasing value of the distortion factor (DF), defined as (1).

$$
D F=\frac{1}{A_{1}}\left(\sum_{k=3}^{39}\left(\frac{A_{k}}{k}\right)^{2}\right)^{1 / 2}
$$

From the solutions shown in figure 1, there have been chosen two cases corresponding to switching intervals $\mathbf{m}=\left[\begin{array}{llll}2 & 7 & 10 & 14\end{array}\right]$ and $\mathbf{m}=\left[\begin{array}{llll}1 & 5 & 10 & 12\end{array}\right]$, in order to compare the differences in the harmonic distribution. Both cases have been simulated in Matlab, with a value of normalized fundamental amplitude of $80 \%$, using a power supply of $100(\mathrm{~V}) \mathrm{DC}$ and a frequency of $50(\mathrm{~Hz})$ for the bipolar PWM signals. Figures 2 and 3 show the obtained results from the simulation.
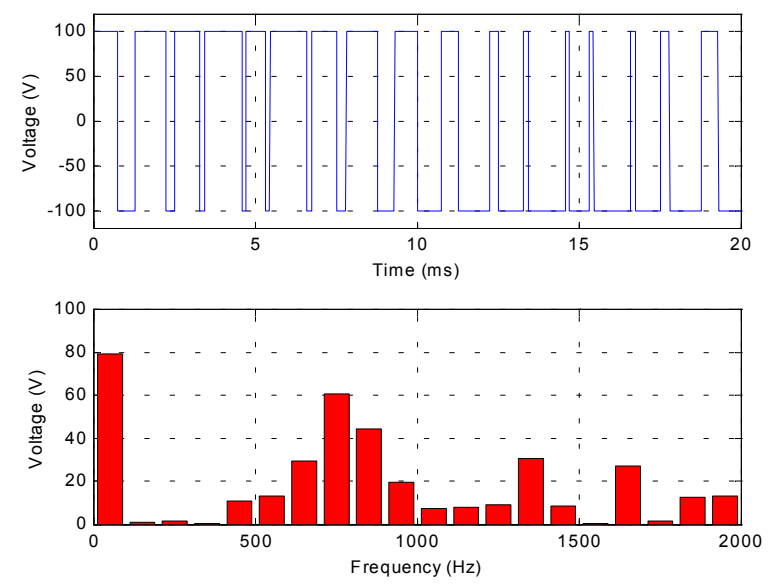

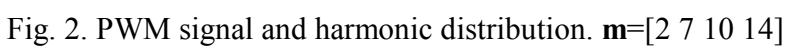
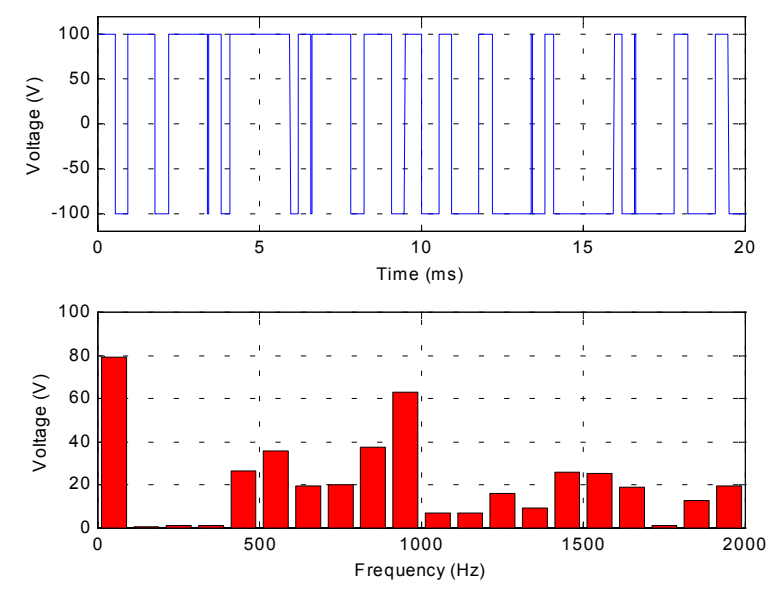

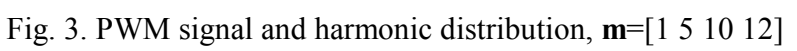

The distortion factors obtained for the signals in figures 2 and 3 are $7.5 \%$ and $8.2 \%$, respectively. Although the difference in the distortion factor is small, the differences in the harmonic distribution are more noticeable. In both cases it can be seen that the $3^{\text {rd }}, 5^{\text {th }}$ and $7^{\text {th }}$ order harmonics are cancelled. This comparison shows the need of obtaining a great number of solutions in order to choose the cases that allow a minimal distortion factor or an harmonic distribution more suited to the application (for instance, in some applications it would be more interesting that the maximum amplitudes appear in the greater order harmonics).

In the present paper it has been developed a faster algorithm that improves both the computation time and the selection criteria of the solutions in order to reduce the PWM harmonic content.

\section{Method analysis}

Since the problem of harmonic elimination is inherent to the frequency domain, the analysis requires the availability of reciprocal conversion tools between Walsh and Fourier transforms. The relationship between Fourier and Walsh coefficients is the starting point to compute the switching angles of the PWM waveform and can be expressed by the transformation (2) [8], where $\mathrm{G}_{\mathrm{F}}$ and $\mathrm{G}_{\mathrm{W}}$ are the Fourier and Walsh coefficients corresponding to the expansion of the PWM signal.

$$
G_{F}=B G_{W}
$$

The Walsh coefficients are obtained as follows:

$$
\boldsymbol{G}_{\boldsymbol{W}}=\boldsymbol{C} \boldsymbol{\delta}+\boldsymbol{D}
$$

where $\boldsymbol{\delta}=\left[\begin{array}{llll}\delta_{1} & \delta_{2} & \ldots & \delta_{M}\end{array}\right]^{T}$ is the vector of switching angle fractions, each one referred to the beginning of its switching interval. $\delta_{\mathrm{i}} \in(0,1)$.

Each quarter period is subdivided in $\mathrm{N}$ intervals, from 0 to $\mathrm{N}-1$, but only $\mathrm{M}$ of which include one, and only one, switching angle. Those intervals, $\mathrm{m}\left(\delta_{\mathrm{i}}\right)$, form the elements of the switching interval vector (4).

$$
\boldsymbol{m}=\left[m\left(\delta_{1}\right) m\left(\delta_{2}\right) \ldots m\left(\delta_{M}\right)\right]
$$

To simplify the notation the elements of vector $\boldsymbol{m}$ would be referred as follows:

$$
\boldsymbol{m}=[m(1) m(2) \ldots m(M)]
$$

The relationship between the fractions $\left(\delta_{i}\right)$ and the switching angles $\left(\alpha_{\mathrm{i}}\right)$ is given by (6) and is represented in figure 4 .

$$
\alpha_{i}=\frac{\pi}{2 N}\left(m(i)+\delta_{i}\right)
$$

Fixing $\mathrm{N}$ as the power of 2 greater or equal to 4 times the number of angles, it can be made that all Walsh functions used in the expansion of the PWM signal have a constant value in each subinterval, reducing the complexity of the algorithm. Another simplification can be obtained fixing the end of the switching in the next interval if the value of $\mathrm{m}(\mathrm{i})$ is less than $(\mathrm{N} / 2)-1$, and in the same interval otherwise.

Figure 4 shows the first quarter of a PWM signal with two switching angles $\left(\alpha_{1}, \alpha_{2}\right)$ at intervals 2 and 6 . In this case: $\mathrm{M}=2, \mathrm{~N}=8, \mathrm{~m}(1)=2$ and $\mathrm{m}(2)=6$. 


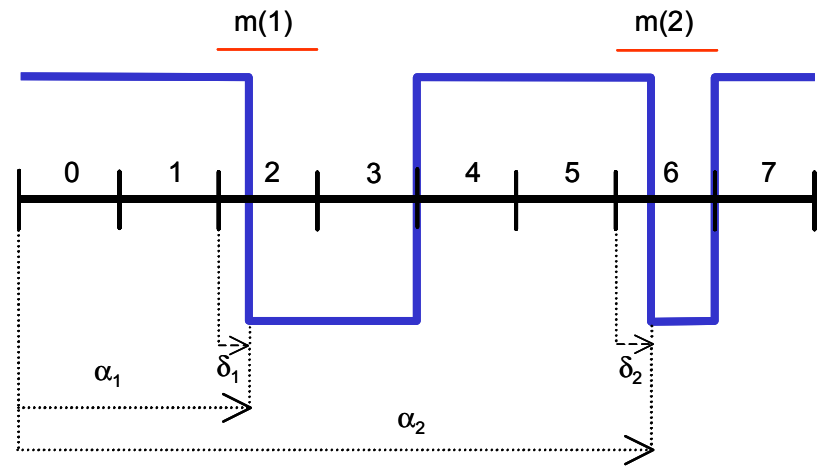

Fig. 4. PWM signal with two switching angles

Taking this into account, matrix $\mathbf{C}$ and column vector $\mathbf{D}$ are easily derived from the Walsh matrix $(\mathbf{W})$ whose elements are obtained from (7):

$$
\mathrm{W}_{\mathrm{i}, \mathrm{j}}=\operatorname{wal}\left(4 i-3, \frac{j-1}{N}\right) \quad i, j=1 \ldots N
$$

Matrix $\mathbf{C}$ is formed with the $\mathrm{M}$ columns of $\mathbf{W}$ corresponding to vector $\mathbf{m}$, multiplied by the factor $2 / \mathrm{N}$.

$$
\mathrm{C}_{\mathrm{i}, \mathrm{j}}=\frac{2}{N} \mathrm{~W}_{\mathrm{i}, \mathrm{m}(\mathrm{j})+1} \quad i=1 \ldots N, j=1 \ldots M
$$

The $\mathrm{N}$ dimension column vector $\mathbf{D}$ is obtained by (9), that makes the base for the application of the algorithm used in this paper.

$$
D_{i}=\frac{2}{N}\left[\frac{1}{2} \sum_{j=1}^{N} W_{i, j}-\sum_{j=1}^{M} W_{i, m(j)+1}-\sum_{j=1}^{M} \varepsilon_{j} W_{i, m(j)+2}\right]
$$

The parameter $\varepsilon_{j}$ takes the value 1 if $m(j)$ is less than $(\mathrm{N} / 2)-1$ and 0 otherwise.

\section{Obtained results}

In order to reduce the computational time, the authors have done a study of the distribution of the switching intervals for 3 to 8 angles.

As an example, the results obtained for 4 and 8 switching angles are depicted in tables I and II, where the more frequent intervals are highlighted.

TABLE I. Distribution of switching intervals (4angles)

\begin{tabular}{|c|c|c|c|c|c|c|c|c|c|c|c|c|c|c|c|c|}
\hline \multirow[b]{3}{*}{ Interval } & \multicolumn{16}{|c|}{ SWITCHING INTERVALS DISTRIBUTION } \\
\hline & \multicolumn{8}{|c|}{ Combinations with A1 range above $20 \%$} & \multicolumn{8}{|c|}{ All combinations } \\
\hline & $m(1)$ & $\mathrm{m}(2)$ & $\mathrm{m}(3)$ & $m(4)$ & $\mathrm{m}(5)$ & $m(6)$ & $\mathrm{m}(7)$ & $m(8)$ & $m(1)$ & $m(2)$ & $\mathrm{m}(3)$ & $m(4)$ & $m(5)$ & $m(6)$ & $m(7)$ & $\mathrm{m}(8)$ \\
\hline 0 & 91 & & & & & & & & 2284 & & & & & & & \\
\hline 1 & 820 & & & & & & & & 6779 & & & & & & & \\
\hline 2 & 1353 & & & & & & & & 8869 & 119 & & & & & & \\
\hline 3 & 294 & 17 & & & & & & & 2642 & 1311 & & & & & & \\
\hline 4 & & 338 & & & & & & & & 3677 & & & & & & \\
\hline 5 & & 913 & & & & & & & & 8254 & 126 & & & & & \\
\hline 6 & & 1004 & & & & & & & & 6335 & 660 & & & & & \\
\hline 7 & & 286 & 6 & & & & & & & 878 & 1208 & & & & & \\
\hline 8 & & & 194 & & & & & & & & 1501 & 1 & & & & \\
\hline 9 & & & 491 & & & & & & & & 4588 & 23 & & & & \\
\hline 10 & & & 587 & & & & & & & & 3976 & 472 & & & & \\
\hline 11 & & & 994 & 1 & & & & & & & 7246 & 426 & & & & \\
\hline 12 & & & 286 & 22 & & & & & & & 1256 & 1687 & & & & \\
\hline 13 & & & & 184 & & & & & & & 13 & 1425 & 3 & & & \\
\hline 14 & & & & 338 & & & & & & & & 1642 & 12 & & & \\
\hline 15 & & & & 947 & & & & & & & & 7089 & 575 & & & \\
\hline 16 & & & & 720 & 95 & & & & & & & 3802 & 2207 & 30 & & \\
\hline 17 & & & & 346 & 376 & & & & & & & 2366 & 3277 & 310 & & \\
\hline 18 & & & & & 752 & & & & & & & 1432 & $\begin{array}{lll}4628 \\
\end{array}$ & 841 & 13 & \\
\hline 19 & & & & & 965 & 45 & & & & & & 201 & 5106 & 2042 & 82 & \\
\hline 20 & & & & & 350 & 254 & & & & & & 8 & 3308 & 3440 & 366 & \\
\hline 21 & & & & & 20 & 726 & & & & & & & 1036 & 4269 & 763 & \\
\hline 22 & & & & & & 691 & 21 & & & & & & 282 & 3547 & 1712 & 46 \\
\hline 23 & & & & & & 571 & 58 & & & & & & 110 & 2691 & 2167 & 305 \\
\hline 24 & & & & & & 231 & 275 & & & & & & 30 & 1718 & 2643 & 550 \\
\hline 25 & & & & & & 40 & 592 & & & & & & & 913 & 3219 & 775 \\
\hline 26 & & & & & & & 707 & & & & & & & 554 & 3654 & 1199 \\
\hline 27 & & & & & & & 654 & & & & & & & 207 & 3672 & 2246 \\
\hline 28 & & & & & & & 237 & 246 & & & & & & 12 & 1674 & 4202 \\
\hline 29 & & & & & & & 14 & 848 & & & & & & & 443 & 3732 \\
\hline 30 & & & & & & & & 760 & & & & & & & 166 & 3703 \\
\hline 31 & & & & & & & & 704 & & & & & & & & 3816 \\
\hline Totals & 2558 & 2558 & 2558 & 2558 & 2558 & 2558 & 2558 & 2558 & 20574 & 20574 & 20574 & 20574 & 20574 & 20574 & 20574 & 20574 \\
\hline
\end{tabular}

\begin{tabular}{|c|c|c|c|c|c|c|c|c|}
\cline { 2 - 9 } \multicolumn{1}{c|}{} & \multicolumn{7}{c|}{ SWITCHING INTERVALS DISTRIBUTION } \\
\cline { 2 - 9 } \multicolumn{1}{c|}{ Combinations with A1 range above 20\% } & \multicolumn{4}{c|}{ All combinations } \\
\hline Interval & $\mathbf{m}(1)$ & $\mathbf{m}(2)$ & $\mathrm{m}(3)$ & $\mathrm{m}(4)$ & $\mathrm{m}(1)$ & $\mathrm{m}(2)$ & $\mathrm{m}(3)$ & $\mathrm{m}(4)$ \\
\hline 0 & 2 & & & & 21 & & & \\
\hline 1 & 21 & & & & 53 & & & \\
\hline 2 & 15 & & & & 65 & & & \\
\hline 3 & 26 & & & & 47 & 6 & & \\
\hline 4 & & 3 & & & & 44 & & \\
\hline 5 & & 10 & & & & 21 & & \\
\hline 6 & & 16 & & & & 25 & & \\
\hline 7 & & 19 & & & & 54 & 8 & \\
\hline 8 & & 10 & 2 & & & 22 & 28 & \\
\hline 9 & & 6 & 10 & & & 14 & 34 & 2 \\
\hline 10 & & & 21 & & & & 51 & 12 \\
\hline 11 & & & 22 & & & & 38 & 22 \\
\hline 12 & & & 9 & 5 & & & 18 & 35 \\
\hline 13 & & & & 23 & & & 7 & 38 \\
\hline 14 & & & & 18 & & & 2 & 36 \\
\hline 15 & & & & 18 & & & & 41 \\
\hline Totals & 64 & 64 & 64 & 64 & 186 & 186 & 186 & 186 \\
\hline
\end{tabular}

TABLE II. Distribution of switching intervals (8angles) 
TABLE III. Reduced switching interval range

\begin{tabular}{|c|c|c|c|c|c|c|c|c|c|c|c|c|c|c|c|c|}
\hline & \multicolumn{2}{|c|}{$m(1)$} & \multicolumn{2}{|c|}{$m(2)$} & \multicolumn{2}{|c|}{$m(3)$} & \multicolumn{2}{|c|}{$m(4)$} & \multicolumn{2}{|c|}{$m(5)$} & \multicolumn{2}{|c|}{$m(6)$} & \multicolumn{2}{|c|}{$m(7)$} & \multicolumn{2}{|c|}{$m(8)$} \\
\hline angles & $\min$ & $\overline{\max }$ & $\min$ & $\max$ & $\min$ & $\max$ & $\min$ & $\max$ & $\min$ & $\max$ & $\min$ & $\max$ & $\min$ & $\max$ & $\min$ & $\max$ \\
\hline 3 & 0 & 6 & 4 & 10 & 9 & 15 & & & & & & & & & & \\
\hline 4 & 0 & 4 & 3 & 7 & 7 & 11 & 11 & 15 & & & & & & & & \\
\hline 5 & 0 & 7 & 5 & 12 & 11 & 18 & 18 & 25 & 24 & 31 & & & & & & \\
\hline 6 & 0 & 6 & 4 & 10 & 9 & 15 & 15 & 21 & 20 & 26 & 25 & 31 & & & & \\
\hline 7 & 0 & 5 & 3 & 8 & 8 & 13 & 12 & 17 & 17 & 22 & 21 & 26 & 26 & 31 & & \\
\hline 8 & 0 & 4 & 3 & 7 & 7 & 11 & 11 & 15 & 15 & 19 & 19 & 23 & 23 & 27 & 27 & 31 \\
\hline
\end{tabular}

In table I, values are shown for the 64 combinations with a fundamental amplitude range above $20 \%$ and for the 186 combinations with solution. It can be observed that each switching interval, m(i), takes values around their nearest quarter, that is: $\mathrm{m}(1)=0 \ldots 3, \mathrm{~m}(2)=4 \ldots 7$, $\mathrm{m}(3)=8 \ldots 11$ and $\mathrm{m}(4)=12 \ldots 15$.

This property is also present in the values shown in table II. In this case, the total number of combinations with solution is 20574, where 2558 of which have an amplitude range above $20 \%$. Those distributions have been taken into account to reduce the number of iterations of the algorithm. The range for each switching interval is shown in table III.

Using these values, the processing times are drastically reduced. Figure 5 compares the differences in computational time between the use of all possible interval combinations or the reduced combinations of intervals derived from the values shown on table III.

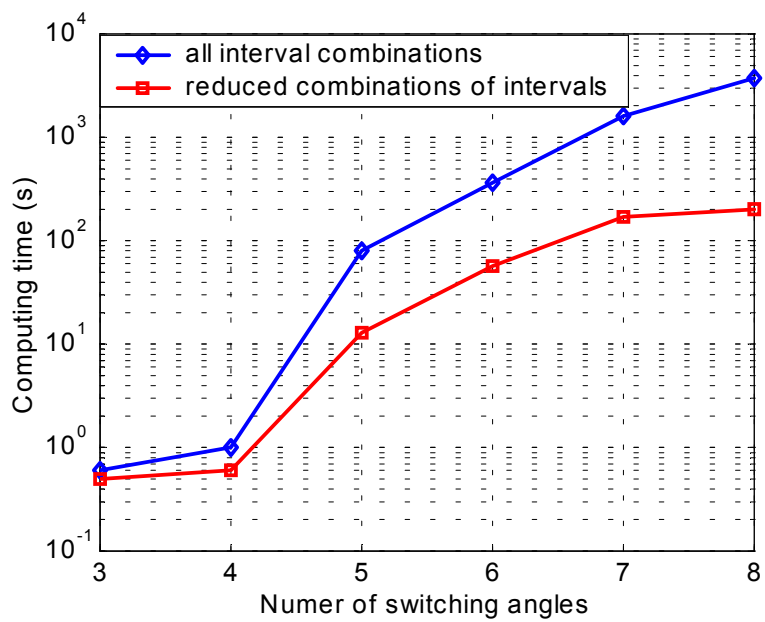

Fig. 5. Computing time comparison

The program was set up in Matlab 5.3 and the processor used was a Pentium 3 at $1.2 \mathrm{GHz}$. For comparison, figure 6 depicts the number of interval combinations obtained in each case.

\section{Conclusions}

It has been developed an algorithm that reduces the computation time of the PWM switching angles using the Walsh transform. The rate of time reduction varies from
1.2 for 3 switching angles to 18.3 for 8 angles, whereas the rate of number of combinations reduction varies from 1.2 for 3 switching angles to 3.2 for 8 switching angles. This shows that the method increases its benefits as increases the number of switching angles.

This method will make possible the study of a bigger number of switching angles that otherwise would have need days of processor time.

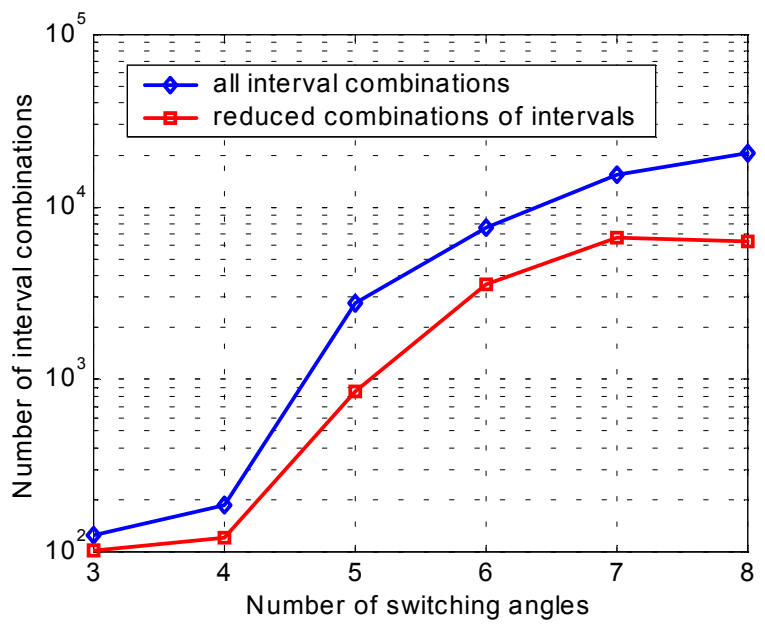

Fig. 6. Comparison of number of interval combinations

\section{Acknowledgement}

The authors would like to thank the "Ministerio de Ciencia y Tecnología" (grant reference MCYT:DPI20012213) for their financial support to the work presented in this paper.

\section{References}

[1] Beauchamp, K.G.: Walsh functions and their applications, Academic Press, 1977.

[2] Swift, F., Kamberis, A.: "A New Walsh Domain Technique of Harmonic Elimination and Voltage Control in Pulse Width Modulated Inverters". IEEE Transactions on Power Electronics, Vol. 8, No. 2, April 1993.

[3] Liang, T.J. O'Connell, R.M. Hoft, R.G.: "Inverter Harmonic Reduction Using Walsh Function Harmonic Elimination Meted", IEEE Transactions on Power Electronics, Vol. 12, 1997, No. 6, pp.971-982.

[4] J. Vicente, R. Pindado, and I. Martínez, "Intervalos de existencia de los ángulos de conmutación para la 
eliminación armónica en convertidores PWM continuaalterna mediante la transformada de Walsh," in Proc. $7^{\circ}$ Seminario Anual de Automática, Electrónica Industrial e Instrumentación (SAAEI'00), Sept. 2000, Terrassa, pp. 179-182.

[5] R. Pindado, I. Martínez, and J. Vicente, "Efectos de la incertidumbre del vector de disparo en la disminución armónica de convertidores DC-AC con PWM mediante transformada de Walsh," in Proc. $8^{\circ}$ Seminario Anual de Automática, Electrónica Industrial e Instrumentación (SAAEI'01), Sept. 2001, Matanzas (Cuba), CD Ref. 02018.

[6] J. Vicente, R. Pindado, and I. Martínez, "Selection Criteria for the Switching Intervals in DC-AC Converters for Harmonic Reduction Using the Walsh Transform," in Proc. 10th IEEE International Power Electronics and
Motion Control Conference (EPE-PMEC 2002), Sept. 2002, Dubrovnik-Cavtat (Croatia), CD Ref. T1-029.

[7] J. Vicente, R. Pindado, and I. Martínez, "Análisis del consumo de potencia en convertidores PWM DC-AC con eliminación armónica programada basada en la transformada de Walsh," in Proc. $9^{\circ}$ Seminario Anual de Automática, Electrónica Industrial e Instrumentación (SAAEI'02), Vol.1, Sept. 2002, Alcalá de Henares, pp.7376.

[8] Siemens, K.H. Kitai, R.: "A Nonrecursive Equation For The Fourier Transform of Walsh Function", IEEE Transactions on Electromagnetic Compatibility, Vol. 15, 1973, No. 2, pp.81-83. 